\title{
Optimal Tuning of Fuzzy Logic Controller Based Speed Control of DC Motor
}

\author{
Mohsin Ali Koondhar ${ }^{1, *}$, Muhammad Usman Keerio ${ }^{1}$, Rameez Akbar Talani ${ }^{1}$, Kamran Ahmed Samo ${ }^{2}$, \\ Muhammad Shahzad Bajwa ${ }^{1}$, Noor Hussain Mugheri ${ }^{1}$, Irfan Ali Channa ${ }^{3}$ \\ ${ }^{1}$ Department of Electrical Engineering, QUEST, Nawabshah, Pakistan. \\ ${ }^{2}$ Department of Electrical Engineering, QUEST Campus Larkana, Pakistan. \\ ${ }^{3}$ Department of Automation, Beijing University Chemical Technology, Beijing, China. \\ ${ }^{*}$ Corresponding author: engr.mohsinkoondhar@quest.edu.pk
}

\section{Abstract}

Fuzzy logic controller (FLC) has become popular in the speed control application of DC motors with automatic adjustment function. In this article, the performance of a specific fuzzy logic controller based DC motor is studied. The exceed speed is observed with a stabilization problem w.r.t time, thus confirming the FLC behavior. Therefore, it must be set to obtain the required performance by applying appropriate expert (fuzzy) rules. The minimum overshoot and installation time can be maintained within the required values. With the help of FLC, the manual adjustment function is gradually eliminated, the intelligent adjustment function is at the center position, and the motor performance is satisfactory. Fuzzy logic controller based DC motor speed control is implemented in MATLAB environment. The results show that the FLC method has the smallest bypass, smallest transient and a steady-state error. In addition, a higher FLC efficiency, as compared with other conventional controllers, was also found.

Keywords-DC motor, Fuzzy Logic Controller, Speed Control, Sensor noise,Tuning methods, Torque

\section{Introduction}

$\mathrm{A}$ DC motor is the part of a type of rotating electrical machine that converts electrical energy into mechanical energy. The least common type depends on the force generated by the magnetic field. Almost all forms of DC motors have certain internal mechanisms, including electro-mechanical mechanisms and digital mechanisms to periodically change the path of modern-day in part of the motor [1]. DC motors are used for lamination, wine winder, paper mills, machine tools, textile mills, etc. The DC motor can produce a huge original torque, and still can achieve speed control in a large range [2-4].

In the industrial field, the development of a DC motor with good performance is the most important task. Essentially, a good performance DC motor system has good dynamic speed tracking and load regulation response. Among different types of motors, DC motors are the most advantageous due to their high compressibility and torque [5]. However, difference in any of the

This is an open access article published by Quaid-e-Awam University of Engineering Science \& Technology, Nawabshah, Pakistan under CC BY 4.0 International License. above parameters may cause damage to the equipment connected to the DC motor. In order to avoid this dual nature of DC motors, we need to control speed and torque. Controlling motor speed means running the motor with desired speed for any variations at the input of motor $[6,7]$.

Motors have been used as main equipment in domestic and industry. In industry, motors have been controlled by computer which is an essential part of various motion control structure [8]. Controllers are used to modify the behavior of this system so that it behaves in a desirable. One of these controllers is fuzzy logic controller $[9,10]$.

The paper is distributed into 5 different sections. Research background has been described in section 1. The modeling of DC motor has been explained in section 2. In section 3. the details about FLC have been discussed. Apart from this, result and discussion has been presented in section 4 . Finally, what we have achieved in this research has been concluded with future work in section 5 . 


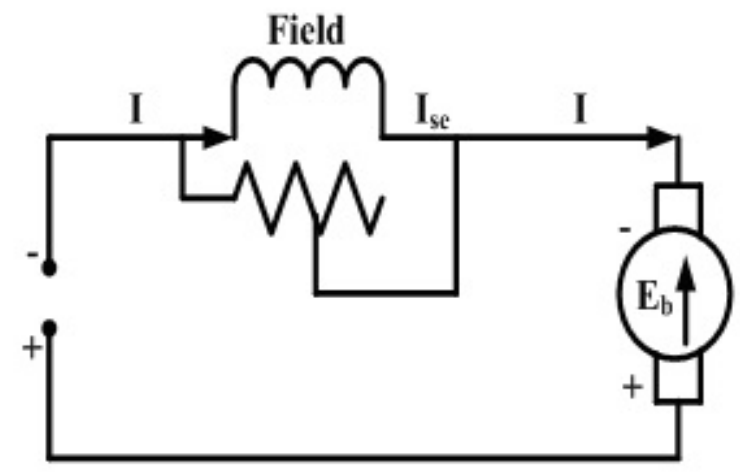

Fig. 1: DC Series Motor Model

\section{Modeling of DC Motor}

The DC motor system model is shown in Figure 1, where $E b, V, I_{a}$ and $R_{a}$ represent back emf, voltage, armature current, and armature resistance, respectively. In DC series motor, due to the field windings connected with the armature in series, the whole current flows through the field windings. In order to withstand the current under full load conditions, the design of the armature field uses a thicker wire and fewer turns. The resistance of the serial field is kept very low.

The rule of deriving the number of coils $N$ of the DC motor is described below.

$$
E_{b}=V-I_{a} R_{a}
$$

But,

$$
E_{b}=\frac{P \phi Z N}{60 A}
$$

Putting Equation 2 in Equation 1, we get,

$$
\frac{P \phi Z N}{60 A}=V-I_{a} R_{a}
$$

Reshuffling above equations, we obtain,

$$
N=\frac{\left(V-I_{a} R_{a}\right)}{\phi} \frac{60 A}{P Z}
$$

where,

$$
K=\frac{60 A}{P Z}
$$

Putting Equation 5 in Equation 4, we obtain,

$$
N=K \frac{\left(V-I_{a} R_{a}\right)}{\phi}
$$

Substituting Equation 1 in Equation 6, we get,

$$
N=K \frac{K_{b}}{\phi}
$$

Altering Equation 7, we get,

$$
N \propto \frac{K_{b}}{\phi}
$$

\section{Fuzzy Logic Controller (FLC)}

FLC is one of the most effective applications of fuzzy group theory. In various engineering fields, FLC has been developed as an equivalent method compared with classic control [11-12]. This project provides the ability of fuzzy logic to plan the DC motor position controller control system. FLC has three main modules: fuzzer (converts the input signal into a fuzzy signal), fuzzy inference motor (uses decision rules to modify the fuzzy signal), and the noise canceller (which converts the output signal of the control unit). The blanking of the signal is used as the input signal control of the system [13].

\subsection{I/P Fuzzy}

Inputs are usually hard or sharp measurements from some measuring instrument and for each fuzzy input specified with a magnetic flux block. These inputs are converted to fuzzy values.

\subsection{Fuzzification}

The first block inside the controller is fuzzification, which converts each input data into an organic degree by searching for one or more organic functions. [14].

\subsection{Knowledge Based / Rule Based}

In a rule-based controller, control strategies are stored in a fairly natural language. For non-professional end users, the basic controller is easy to understand and maintain, and traditional techniques can be used to implement equivalent controllers.

\subsection{Fuzzy Logical}

The fuzzy engine is the core of the fuzzy logic controller. It has the ability to simulate human decisions based on fuzzy concepts and use fuzzy embedding (fuzzy relations) and fuzzy logic inference rules to infer fuzzy control actions.

\subsection{Defuzzification}

All the actions activated, combined and converted into a single non-fuzzy output signal form the control signals of the system. The output level is based on system rules and location.

\subsection{Fuzzy Output}

Fuzzy output can use the center of gravity, or weighted average to calculate the net output value. Figure 2 shows the basic structure of FLC and the controller between the pre-processing and post-processing blocks. Total six blocks have been used for specific characteristic of a fuzzy controller to support a design procedure. 


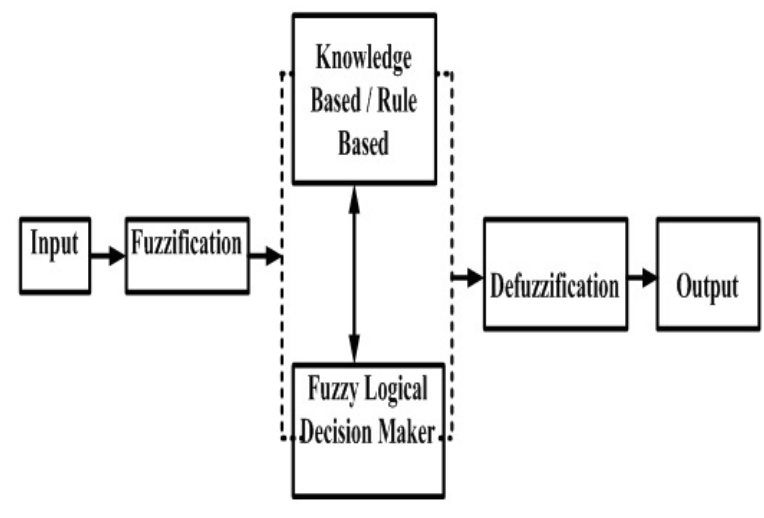

Fig. 2: FLC Structures [15][16]

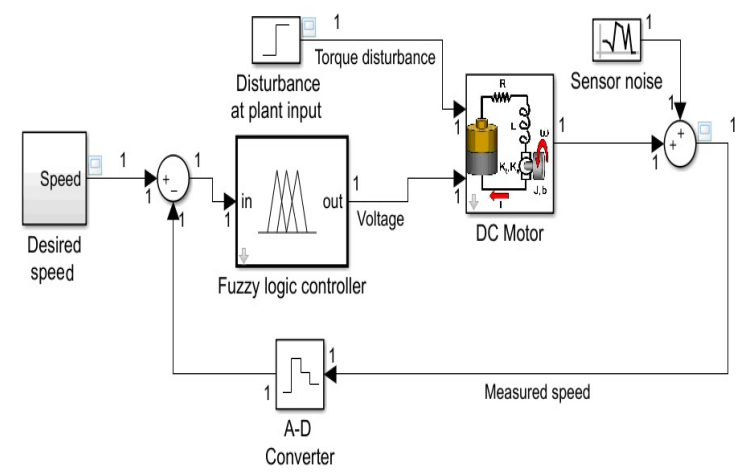

Fig. 3: Matlab based model of DC Motor

\section{Results \& Discussion}

We simulated the direct current motor speed control based on FLC in Matlab. Its model is shown in Figure 3 and parameters of FLC based proposed controller is illustrated in Figure 4. Parameters for DC motor are presented in Table 1. A different block of MATLAB model of DC motor has been shown in Figure 3. A FLC controller is applied to analysis the behavior of the DC motor by giving desired speed with torque disturbance. Figure 5 shows the comparative analysis between desired value (red line) and measured value (blue line) for of DC motor. Furthermore, disturbances of voltage and torque are also illustrated. Torque is in

\begin{tabular}{|l|l|l|}
\hline S. No & Parameter Description & Parameter Value \\
\hline 1 & Armature Resistance (Ra) & $0.4 \Omega$ \\
\hline 2 & Armature inductance (La) & $0.0024 \mathrm{H}$ \\
\hline 3 & Mechanical inertia(jm) & $0.20 \mathrm{Kg} . \mathrm{m} 2$ \\
\hline 4 & Armature voltage (Va) & $240 \mathrm{~V}$ \\
\hline 5 & Back emf constant (k) & $1.65 \mathrm{~V} / \mathrm{rad} / \mathrm{sec}$ \\
\hline 6 & Friction coefficient (bf) & $0.007 \mathrm{~N} . \mathrm{m} / \mathrm{rad} / \mathrm{sec}$ \\
\hline 7 & Motor Torque Constant & $1.0 \mathrm{~N} . \mathrm{m} / \mathrm{Amp}$ \\
\hline 8 & Rated Speed of Motor & $1800 \mathrm{r} . \mathrm{p} . \mathrm{m}$ \\
\hline
\end{tabular}

TABLE 1: Parameters of the Model steady state from 0 to 5 . After that, some disturbance occurs in torque in the interval of 0 to 0.2 . From the results, it is evident that fuzzy is a basic controller based on the system's mathematical model to be controlled. It successfully overcomes the steady-state error limitation of the fuzzy controller, as steady-state error in fuzzy controllers is zero (0). Steady-state error to over-shoot zero error is monitored. The gain of the controller raises up by decreasing the overshoot, but at the end rise time also is enhanced. Overall, the fuzzy controller provides all of the linear controllers in its class with better speed response.

\section{Conclusion}

This paper presents the design of a fuzzy controller of a DC motor for speed control. For most of the systems, fuzzy logic controllers provide good and vigorous performance. The program's graphical representation provides us with a good understanding of the structure and data flow. It is better for application control, while MATLAB is better for manipulating data. This work proves that the fuzzy controller exhibits robust control based on parameters with other controllers.

In future, we aim to analyze the performance of DC motor by FLC in a laboratory.

\section{References}

[1] M. Jibril, M. Tadese, E. A. Tadese, "Comparison of DC motor speed control performance using fuzzy logic and model pre-dictive control method", International Research Journal of Modernization in Engineering Technology and Science, vol. 2, no. 1, pp. 141-145, 2020.

[2] M. A. Koondhar, A. A. Malak, M. A. Koondhar, \& I. A. Channa, "Experimental based Comparative Analysis and Characteristics of DC Series Motor by using Different Techniques", Sukkur IBA Journal of Emerging Technologies, vol. 3, no. 1, pp. 1-15, 2020.

[3] P. Malviya, \& M. Dubey, "Speed control of DC Motor a Review", International Journal of Engineering Sciences \& Research Technology, 2015.

[4] M. A. Koondhar, A. K. Junejo, A. S. Saand, \& M. U. Keerio, "Speed Control of DC Series Motor with Conventional and PLC Techniques", International Journal of Information Technology and Electrical Engineering, vol. 5, no. 4, pp. 21$26,2016$.

[5] A. K. Sahoo, S. Suman, "Speed Control of DC motor Using Hybrid", International Journal of Advanced Research in Electri-cal, Electronics and Instrumentation Engineering Fuzzy-PID Controller, vol. 6, no. 11, pp. 1-6, 2017.

[6] I. I. Ekpoudom, I. E. Archibong, \& U. T. Itaketo, "Speed Control of DC Motor on Load Using Fuzzy Logic Controller (A Case Study of Emergency Lube Oil Pump Motor of H25 Hitachi Turbine Generator)", Nigerian Journal of Technology, vol. 36, no. 3, pp. 867-875, 2017.

[7] K. Sharma, \& D. K. Palwalia, "A modified PID control with adaptive fuzzy controller applied to DC motor", In IEEE International Conference on Information, Communication, Instrumentation and Control, pp. 1-6, 2017. 


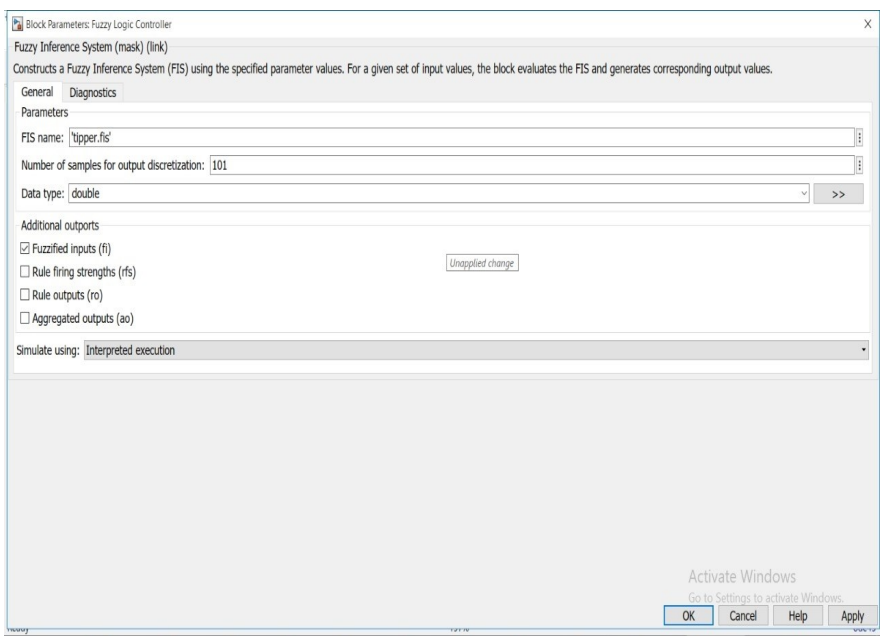

Fig. 4: Block parameters of proposed fuzzy logic controller

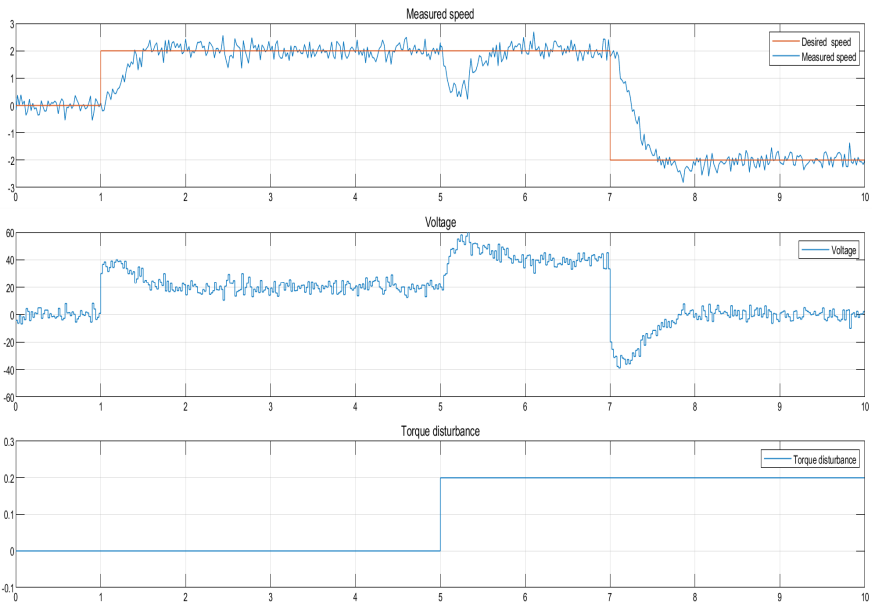

Fig. 5: Comparison of Speed-Torque disturbance of DC Motor

[8] A. K. Rajagiri, S. Rani, \& S. S. Nawaz, "Speed control of DC motor using fuzzy logic controller by PCI 6221 with MATLAB". In E3S Web of Conferences EDP Sciences, vol. 87, p. 01004, 2019.

[9] Y. A. Almatheel, \& A. Abdelrahman, "Speed control of DC motor using Fuzzy Logic Controller. In 2017 International IEEE Conference on Communication, Control, Computing and Electronics Engineering, pp. 1-8, 2017.

[10] W. Gubara, M. Elnaim, \& S. F. Babiker, "Comparative study on the speed of DC motor using PID and FLC", In IEEE Conference of Basic Sciences and Engineering Studies, pp. 24-29, 2016.

[11] S. Sharma, S. S. Oberoi, \& S. Nair, "Speed Control Method of DC series motor", International Journal of Innovative Research in Technology, vol. 1, no. 6, pp. 1450-1453, 2014.

[12] Z. A. S. Rahman, "Design a fuzzy logic controller for control-ling position of dc motor", Int. J. Comput. Eng. Res. Trends, 4, 285-289, 2017.

[13] M. A. Ahmad, \& P. Rai, "Speed control of a DC motor using Controllers", Automation, Control and Intelligent Systems, vol. 2, no. 6-1, pp. 1-9, 2014.

[14] A. A. Bature, M. Muhammad, \& A. M. Abdullahi, "Design and Real Time Implementation of Fuzzy Controller for DC
Motor Position Control", International journal of scientific \& technology research, 2, pp. 254-256, 2013.

[15] J. Chakravorty, \& R. Sharma, "Fuzzy logic based method of speed control of DC motor", International journal of emerging technology and advanced engineering, vol. 3 , no. 4, pp. 64-66, 2013.

[16] S. Saat, "DC motor speed control using fuzzy logic controller", (Doctoral dissertation, Universiti Tun Hussein Onn Malaysia), 2014. 